09

\title{
Исследование распределенного $H$-параметра анизотропного оптического волокна в многослойной катушке волоконно-оптического гироскопа
}

\author{
(C) А.Б. Мухтубаев, ${ }^{1}$ С.М. Аксарин, ${ }^{1}$ В.Е. Стригалев, ${ }^{1}$ Р.Л. Новиков ${ }^{1,2}$ \\ ${ }^{1}$ Университет ИТМО, \\ 197101 Санкт-Петербург, Россия \\ ${ }^{2}$ АО Концерн „ЦНИИ Электроприбор“, \\ 197046 Санкт-Петербург, Россия \\ e-mail: mukhtubaev.ab@gmail.com
}

(Поступило в Редакцию 7 июля 2016 г. В окончательной редакции 6 февраля 2017 г.)

Проведено исследование распределенного $H$-параметра в анизотропном оптическом волокне с эллиптической напрягающей оболочкой в многослойной катушке волоконно-оптического гироскопа. Длина волокна в каждом слое составляла $\sim 50 \mathrm{~m}$, количество слоев -5 . Исследования проводились с тремя вариантами исполнения катушки: в первой катушке слои пропитывались эпоксидной смолой, во второй катушке слои пропитывались материалом на основе силикона и в третьей катушке слои укладывались без пропитки („сухая““ намотка). Выявлено различное влияние сдавливающих механических напряжений на распределенный $H$-параметр исследуемого волокна в зависимости от варианта пропитки катушки.

DOI: 10.21883/JTF.2017.08.44730.1976

\section{Введение}

Анизотропные оптические волокна с двулучепреломлением широко используются при проектировании волоконно-оптических датчиков интерферометрического типа и оптических трактов передачи информации. Такие волокна обладают свойством сохранять линейнополяризованное излучение по всей своей длине. Эффект сохранения поляризации достигается двумя способами: либо индуцированием в процессе вытяжки волокна механической напряженности материала, либо за счет создания асимметрии в структуре волокна.

Эффект рассогласования поляризации интерферирующих волн приводит к возникновению ошибок в показании высокоточных приборов, а также к искажению сигнала интерферометра [1]. Наиболее важными параметрами анизотропных оптических волокон с двулучепреломлением являются: величина модового двулучепреломления (фазовое двулучепреломление), величина группового двулучепреломления (поляризационно-модовая дисперсия), дисперсия двулучепреломления, коэффициент экстинкции сохранения поляризации и $H$-параметр. При проектировании интерферометрических датчиков необходимо использовать анизотропное оптическое волокно с $H$-параметром около $10^{-6} 1 / \mathrm{m}[2-6]$.

В работах [7-10] были проведены исследования влияния радиуса намотки анизотропного оптического волокна с эллиптической напрягающей оболочкой и величины натяжения на величину $H$-параметра. Зачастую в схемах волоконно-оптических датчиков используются элементы, конструкция которых представляет собой многослойную катушку с оптическим волокном. Целью настоящей работы является исследование распределенного $H$-параметра анизотропного оптического волокна с эллиптической напрягающей оболочкой в многослойной конструкции катушки.

\section{Исследование распределенного H-параметра в многослойной катушке}

В настоящей работе объектом исследования являлось анизотропное оптическое волокно с эллиптической напрягающей оболочкой (рис. 1). Исследуемое волокно было покрыто стандартным акрилатным покрытием. Волокно наматывалось на катушку из керамики диаметром $18 \mathrm{~cm}$ виток к витку пятью слоями (рис. 2). Каждый слой представлял собой отдельный отрезок оптического волокна длиной $\sim 50 \mathrm{~m}$.

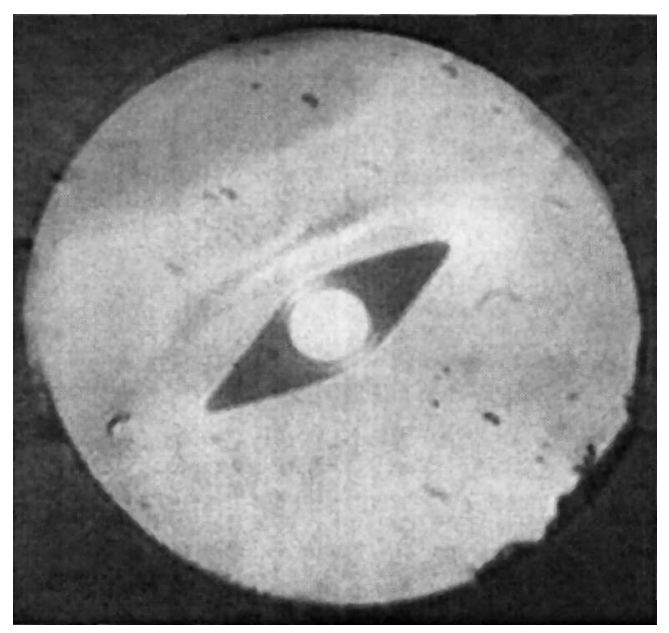

Рис. 1. Форма торца исследуемого анизотропного оптического волокна с эллиптической напрягающей оболочкой. 


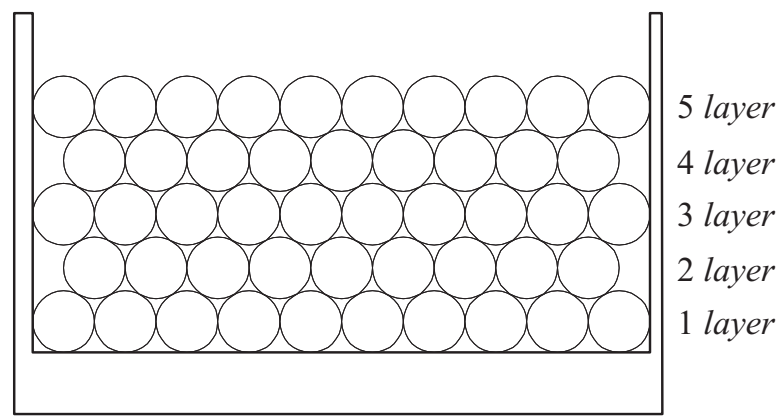

Pис. 2. Схема укладки оптического волокна в катушке.

Исследования проводились с тремя вариантами исполнения катушки. В первом случае 5 слоев оптического волокна наматывались без использования какойлибо пропитки („сухая“ намотка). Во втором случае в качестве пропитки использовалась эпоксидная смола, которая заполняла пространство между волокнами, и в третьем случае использовался специальный материал на основе силикона.

Продольная сила натяжения оптического волокна на катушку выбиралась по принципу минимальных поляризационных преобразований в исследуемом волокне, которые зависят от силы натяжения [7], и составила $0.1 \mathrm{~N}$.

\section{Схема экспериментальной установки}

Для анализа распределенного $H$-параметра в анизотропных оптических волокнах классические методы (к примеру, метод скрещенных поляризаторов $[11,12]$ ) неприменимы. Инструментом для измерения распределенных поляризационных преобразований может служить методика, основанная на применении широкополосной интерферометрии. В данной методике используются широкополосный источник излучения и сканирующий интерферометр с анализатором на входе для выделения обеих ортогональных поляризационных мод $[13,14]$. В настоящей работе в качестве инструмента для анализа распределенного $H$-параметра в анизотропном оптическом волокне с эллиптической напрягающей оболочкой использовался поляризационный сканирующий интерферометр Майкельсона. Когда в интерферометре создается разность оптических путей, превышающая длину декогерентности, амплитуда интерференционного сигнала стремится к нулю. Таким образом, можно добиться высокой точности в определении места локального преобразования в оптическом тракте, а по амплитуде интерференционного сигнала дать оценку величине поляризационного преобразования [13].

При проведении исследований использовался широкополосный источник излучения суперлюминесцентный диод ThorLabs S5FC1005SXL с центральной длиной волны $1575 \mathrm{~nm}$ и полушириной спектра $45 \mathrm{~nm}$. Линейнополяризованное излучение вводится в исследуемое оптическое волокно под некоторым углом $\alpha$ к одной из поляризационных осей (рис. 3). При сканировании исследуемого оптического волокна смещением зеркала интерферометра Майкельсона на интерферограмме будут возникать интерференционные пики. Минимизируя величину последнего пика, можно добиться ввода излучения в поляризационную ось волокна под углом $\alpha=0^{\circ}$. По среднему значению видности интерференционной картины в области намотки волокна можно определить величину распределенного $H$-параметра для этой области.

В результате сканирования исследуемой катушки поляризационным интерферометром Майкельсона были получены видности интерференционных картин для каждого из слоев анизотропного оптического волокна с эллиптической напрягающей оболочкой. По среднему уровню определяется среднее значение видности интерференционной картины, затем вычисляется значение распределенного $H$-параметра по формуле [1]:

$$
H=V_{c}^{2} \cdot L_{d}^{-1},
$$

где $H$ - величина поляризационных преобразований, $H$-параметр; $V_{c}$ - видность интерференционной картины; $L_{d}$ - длина деполяризации исследуемого волокна.

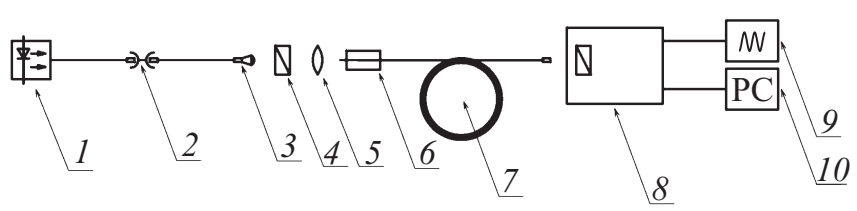

Рис. 3. Схема экспериментальной установки по исследованию распределенного $H$-параметра анизотропного оптического волокна с эллиптической напрягающей оболочкой в многослойной катушке: 1 - широкополосный источник излучения, $2-$ оптическая розетка, 3 - коллиматор, 4 - поляризатор, 5 объектив, 6 - микропозиционер, 7 - объект исследования, 8 - поляризационный интерферометр Майкельсона, 9 осциллограф, 10 - персональный компьютер.

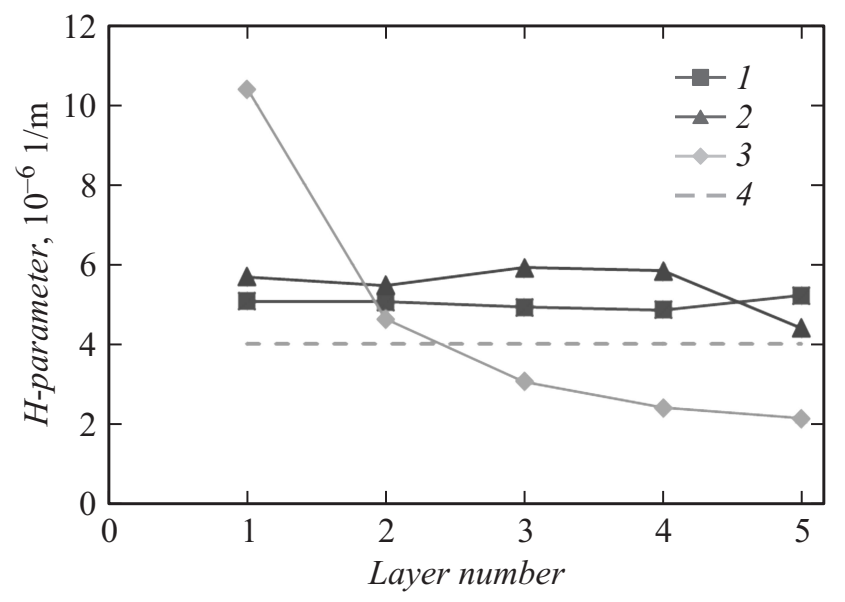

Рис. 4. $H$-параметр каждого слоя в многослойной катушке с анизотропным оптическим волокном с эллиптической напрягающей оболочкой: $1-$ „сухая“ намотка, $2-$ пропитка эпоксидной смолой, 3 - пропитка силиконом, 4 - паспортное значение. 
Значение длины деполяризации анизотропного оптического волокна определяется как $[1,14]$

$$
L_{d}=\lambda^{2} \cdot(\Delta \lambda \cdot \Delta n)^{-1},
$$

где $\lambda$ - центральная длина волны источника оптического излучения $(1575 \mathrm{~nm}), \Delta \lambda-$ ширина спектра источника оптического излучения $(45 \mathrm{~nm}), \Delta n-$ разница эффективных показателей преломления поляризационных мод в двулучепреломляющем волокне $\left(6 \cdot 10^{-4}\right)$. Подставив необходимые данные в формулу, получим значение длины деполяризации исследуемого анизотропного оптического волокна, равное $0.09 \mathrm{~m}$.

На рис. 4 представлена зависимость распределенного $H$-параметра от номера слоя в многослойной катушке для трех вариантов исполнения: „сухая“ намотка, пропитка эпоксидной смолой, пропитка силиконом.

\section{Заключение}

Из полученных результатов видно, что характер зависимости распределенного $H$-параметра анизотропного оптического волокна с эллиптической напрягающей оболочкой для разных катушек различается. Так, значение распределенного $H$-параметра на нижнем первом слое каждого варианта катушки значительно выше паспортного значения. Такие значения распределенного $H$-параметра свидетельствуют о высоких поляризационных преобразованиях, возникающих в оптическом волокне за счет различных механических воздействий (сдавливание, скрутка, растяжение, микроизгибы), что, в свою очередь, может приводить к некорректной работе волоконно-оптических датчиков интерференционного типа.

Однако по мере увеличения номера слоя для катушки, пропитанной силиконом, величина распределенного $H$-параметра уменьшается, что характеризует уменьшение поляризационных преобразований, возникающих в слое оптического волокна за счет снижения сдавливающих механических напряжений.

Для катушки с пропиткой из эпоксидной смолы и с „сухой“ намоткой величина распределенного $H$-параметра превышает паспортное значение и сохраняется в каждом слое. Намотка катушки „в сухую“ обеспечивает минимальное повышение $H$-параметра относительно паспортного значения, однако такой вариант намотки не представляет практического интереса, поскольку для обеспечения сохранения свойств намотки при различных эксплуатационных вибрационных воздействиях необходимо производить взаимную фиксацию витков катушки между собой. Особенно остро задача стабилизации формы и расположения витков катушки стоит перед разработчиками волоконно-оптических гироскопов, поскольку ориентация катушки в пространстве вносит прямой вклад в измеряемую угловую скорость вращения.

В заключение отметим, что при проектировании высокоточных волоконно-оптических датчиков необходимо учитывать такой параметр анизотропного оптического волокна с двулучепреломлением, как распределенный $H$-параметр, который свидетельствует о наличии поляризационных преобразований в волокне. Получили, что с использованием специальных пропиток, например на основе силикона, уменьшаются поляризационные преобразования, начиная с третьего слоя (рис. 4). Такая пропитка позволяет получить значение распределенного $H$-параметра меньшее, чем при „сухой“ намотке.

Настоящая работа выполнена в Университете ИТМО при финансовой поддержке Министерства образования и науки Российской Федерации (уникальный идентификатор проекта: RFMEFI57815X0109, соглашение № 14.578.21.0109).

\section{Список литературы}

[1] Lefevre H.C. Fiber-Optic Gyroscopes. Boston: Artech House, 1993. $313 \mathrm{p}$.

[2] Автор. канд. дис. Аксарин С.М. Исследование поляризационных методов и технологий согласования волоконнооптических и интегрально-оптических волноводов. СПб. 2014. $116 \mathrm{c}$.

[3] Kaminow I.P. // Appl. Sci. Res. 1984. Vol. 41. N 3-4. P. $257-$ 270.

[4] Jia M., Yang G. // Chin. J. Aeronautics. 2011. Vol. 24. N 5. P. 640-647.

[5] Shute Sr.M.W., Brown C.S., Jarzynski J. // J. Opt. Society America A. 1997. Vol. 14. N 12. P. 3251-3261.

[6] Котов О.И., Лиокумович Л.Б., Медведев А.В. // ЖТФ. 2007. Т. 77. Вып. 9. С. 102-107.

[7] Мухтубаев А.Б., Аксарин С.М., Стригалев В.Е., Новиков Р.Л. // Научно-технический вестн. информационных технологий, механики и оптики. 2015. Т. 15. № 5. С. $803-$ 808.

[8] Аксарин С.М., Архипов С.В., Варжель С.В., Куликов А.В., Стригалев B.E. // Научно-технический вестн. информационных технологий, механики и оптики. 2013. № 6 (88). C. $22-26$.

[9] Мешковский И.К., Киселев С.С., Куликов А.В., Новиков Р.Л. // Изв. вузов. Приборостроение. 2010. Т. 53. № 2. C. $47-51$.

[10] Шрамко О.А., Рупасов А.В., Новиков Р.Л., Аксарин С.М. // Научно-технический вестн. информационных технологий, механики и оптики. 2014. № 1 (89). С. 26-31.

[11] Иродов И.Е. Волновые процессы. Основные законы. 4-е изд. М.: БИНОМ, 2007. $263 \mathrm{c.}$

[12] Sezerman O., Best G. // Laser Focus World. 1997. Vol. 33. N 12. P. 27-30.

[13] Аксарин С.М., Стригалев В.E. Методика и аппарат исследования локальных преобразований в оптических волокнах с двулучепреломлением // Сб. тезисов докладов конгресса молодых ученых. СПб. 2012. Вып. 2. С. 44-45.

[14] Martin P., Le Boudec G., Lefevre H.C. // Proc. SPIE. 1992. Vol. 1585. P. 173-179. 